\title{
Kırsal turizm planlamasında farklı peyzaj tiplerinin görsel kalite yönünden değerlendirilmesi*
}

\author{
Meliha AKLIBAŞINDA ${ }^{1}$, Yahya BULUT²
}

${ }^{1}$ Nevşehir Hacı Bektaş Veli Üniversitesi, Mühendislik-Mimarlık Fakültesi, Peyzaj Mimarlığı Bölümü, 50300, NEVŞEHİR

${ }^{2}$ Atatürk Üniversitesi, Mimarlık ve Tasarım Fakültesi, Peyzaj Mimarlı̆̆ı Bölümü, 25240, ERZURUM

* Bu makale doktora tez çalışmasından üretilmiş olup 'International the West of the East, the East of the West' isimli konferansta sunulmuş, özet bildiri olarak basılmıştır.

Alınıș tarihi: 20 Temmuz 2017, Kabul tarihi: 4 Ekim 2017

Sorumlu yazar: Meliha AKLIBAȘINDA,e-posta: melihaaklibasinda@nevsehir.edu.tr

$\ddot{0} \mathbf{z}$

Doğal ve kültürel kaynakların analizi temelinde yapılan peyzaj planlamasında özellikle turizm ve rekreasyon faaliyetleri planlanırken önemli bir çekici unsur olan görsel kalite göz ardı edilmemelidir. Görsel kalite analizi, peyzajın fiziksel özelliklerinin algısal parametrelerle ilişkilendirilerek peyzajın görsel kalitesinin ve görsel tercihlerin saptamasını sağlayan bir yöntemdir. $\mathrm{Bu}$ sayede nitel tanımlamalar nicel verilere dönüştürülerek bir alanın görsel potansiyeli ortaya konulabilmektedir.

Bu çalışmada topoğrafik yapısı ve konumu nedeniyle değişik tipte peyzaj karakterlerini içeren Yahyalı'nın (Kayseri) görsel kalitesi değerlendirilmiştir. İlçenin karakteristik yapısını şelaleler, orman, köy, dağ ve vadi peyzajları oluşturmaktadır. Değişik peyzaj tipleri içerisinde insanların görsel yönden en çok tercih ettiği alanları belirlemek amacıyla 175 kişiyle anket çalışması yürütülmüştür. Her bir peyzaj tipini temsil eden 4'er (toplam 20) fotoğraf üzerinden alanın manzara güzelliği ve manzara güzelliğinin canlılık, renk etkisi, heyecan vericilik, rahatlatıcılık/huzur vericilik, ilginçlik ve güven vericilik parametreleriyle ilişkisi irdelenmiştir. Anket çalışması sonucu manzara güzelliği puanlarına göre ilçede şelaleler en çok tercih edilen peyzaj bileşeni olurken $(\mathrm{M}=3.78)$ bunu sırasıyla vadi oluşumları $(M=3.74)$, ormanlık alanlar $(M=3.49)$, köy yerleşimleri $(M=3.40)$ ve dağlık alanlar $(M=3.34)$ takip etmiştir. Bunun yanı sıra her bir peyzaj tipi içerisinde de insanların tercihleri incelenerek görsel potansiyeli yüksek olan alanlara ilişkin değerlendirmeler yapılmıştır.

Anahtar kelimeler: Görsel kalite analizi, kırsal peyzaj, manzara güzelliği, peyzaj karakteri

Evaluation of different landscape types in terms of visual quality at rural tourism planning

\section{Abstract}

Planning studies are based on the detailed analysis of natural and cultural resources. The richness of these also increases visual quality of an area. Visual quality is an important attractive factor on tourism and recreation activities. For this reason, landscape components and visual potential of the area should be determined in tourism and recreation planning. Visual quality assessment is a method that determines the beauty of the landscapes and visual preferences by correlating physical properties of the landscape with perceptual parameters. Thus, qualitative descriptions can be transformed into quantitative data and visual potential of an area can be exhibited.

In this study, the visual quality of Yahyalı (Kayseri), which includes various types of landscape characters due to its topographic structure and location, was evaluated. The characteristic landscape features of the district are the waterfalls, forests, villages, mountains and valleys. A survey study was carried out with 175 people to determine the most visually preferred landscape type of the district. 20 
photographs (4 photos for each landscape type that represents the area best) were shown to people. According to the survey results, the scenic beauty of the area and the relationships between scenic beauty and sensorial parameters (vividness, colorfulness, exciting, peacefulness, being interesting, confidence) were examined. According to the scores of scenic beauties, the waterfalls $(M=3.78)$ were the most preferred landscape component in the district. Waterfalls were followed respectively by valleys $(M=3.74)$, forests $(M=3.49)$, village settlement $(\mathrm{M}=3.40)$ and mountains $(\mathrm{M}=3.34)$.

Key words: Character of landscape, rural landscape, scenic beauty, visual quality analysis

\section{Giriş}

Turizm planlamasında görsel kalite analizi yoluyla bir alanın insanlar tarafından en çok beğenilen ve tercih edilen doğal ve kültürel peyzaj özelliklerinin ortaya konulması, doğrudan veya dolaylı olarak görselliğe dayanan turistik aktiviteler için önem taşımaktadır.

Turistik ve rekreasyonel aktivitelerde bir yerin çekiciliğini artıran ana faktörden biri olan manzara güzelliği bir alanın çekiciliğini artırarak ekonomik faydalar sağlamasının yanı sıra insanların rekreasyonel faaliyetlerinin kalitesini de doğrudan etkilemektedir (Clay and Daniel, 2000). Bu nedenle turizm endüstrisinin gelişmesinde önemli bir faktör olan görsel çekiciliğin korunması için uygun peyzaj yönetim planları uygulanmalıdır (Zube ve ark., 1982).

Görsel kalite değerlendirmesi çevresel algılama araştırmalarında aktif bir çalışma alanı olduğu kadar, çevre planlama ve yönetiminin de önemli bir bileşendir ve dolayısıyla değerlendirilmesi gereken halkalardan biridir (Meitner, 2004). Peyzajın görsel kalitesi; insanların kavrama özellikleri, uzman bakışı ve doğrudan duyulara dayalı algılanabilir süreçler yolu ile ortaya konulabilecek bir kavramdır. Sistematik görsel peyzaj kalitesi değerlendirmesi 20. yüzyılın son yarısında ortaya konmuş ve geliştirilmiştir. Çevre yönetiminde ve politikasında literatür tabanı ile kabul gören bir bilimsel araştırma alanı haline gelmiştir (Daniel, 2001).

Görsel kalite değerlendirmesi çalışmalarında uzman yaklaşımı ve algıya dayalı yaklaşım olmak üzere iki değerlendirme yöntemi ön plana çıkmaktadır. Uzman yaklaşımı çoğunlukla çevre yönetimi uygulamalarında, algıya dayalı yaklaşım ise araştırmalarda yoğunlaşmıștır. Her iki yaklaşım da peyzaj kalitesinin biyofiziksel özellikleri ile izleyicinin algısal/yargısal süreçleri arasındaki etkileşimden doğduğunu kabul etmektedir. Uzman yaklaşımı; peyzaj kalitesinin genel belirleyicileri olarak kabul edilen form, çizgi, çeşitlilik, birlik gibi tasarım öğelerinin insanların algıları ile ölçülmesini temel almaktadır. Peyzajın biyofiziksel özellikleri (dağlar, göller, ağaçlar vs.), formal özelliklere (form, çizgi, doku, renk vs.) ve bu özellikler arasındaki ilişkilere (çeşitlilik, birlik, canlılık, uyum vs.) dönüştürülür. Daha sonra alanlar düşükten yüksek kaliteye doğru sıralanır. Algıya dayalı yaklaşım ise peyzajın biyofiziksel özelliklerini doğrudan duyulara dayalı algılanabilir süreçler yoluyla değerlendiren, kavrama ile ilgili özellikleri kullanan bir yaklaşımdır. Genellikle çeşitli anket araştırması ve psikolojik ölçüm metotları, algılanan peyzaj görsel kalitesinin sayısal ölçümlerini elde etmek için kullanılmaktadır. Algılanan peyzaj kalitesinin göstergeleri, gözlemci gruplardan elde edilen peyzaj tercihleri (genellikle fotoğraflar üzerinden), derecelendirme veya sınıflandırmalarına dayanmaktadır. Uzman yaklaşımın aksine algıya dayalı değerlendirmeler yüksek düzeyde güvenilirlik sağlamaktadır (Daniel, 2001; Fuente de Val ve ark., 2006).

Görsel peyzaj kalitesini değerlendirmede çalışmanın amacına göre değişik parametreler kullanılmaktadır. $\mathrm{Bu}$ parametrelerle manzara güzelliği ve insanların alanı tercih düzeyleri ile ilişkileri sorgulanmaktadır. Araştırmanın amacı, doğal güzelliği ve farklı kırsal peyzaj özellikleriyle bulunduğu bölgede özgün bir yapıya sahip Yahyalı ilçesinin görsel niteliği ile çekiciliği yüksek alanlarını ve peyzaj tiplerini ortaya koymak amacıyla algıya dayalı görsel kalite analizi yapılmıştır.

\section{Materyal ve Yöntem}

\section{Materyal}

Çalışmanın ana materyalini Kayseri İli'ne bağlı Yahyalı İlçesi oluşturmaktadır. İlçe, Kayseri'nin güneyinde kurulmuş olup $37^{\circ} 41^{\prime}$ ve $38^{\circ} 16^{\prime}$ kuzey enlemleri ile $35^{\circ} 9^{\prime}$ ve $35^{\circ} 43^{\prime}$ doğu boylamları arasında yer almaktadır (Şekil 1). Kayseri il merkezine uzaklığı 87 km'dir.

Yahyalı, doğusu, batısı ve güneyi dağlarla çevrili, kuzeyi vadi düzlükleri ve ovalık olan bir coğrafyada yer almaktadır. İlçe $500 \mathrm{~m}$. ile $3750 \mathrm{~m}$. arasında değişen yükseltilere sahip olup ilçe merkezinin rakımı 1210 m'dir. 


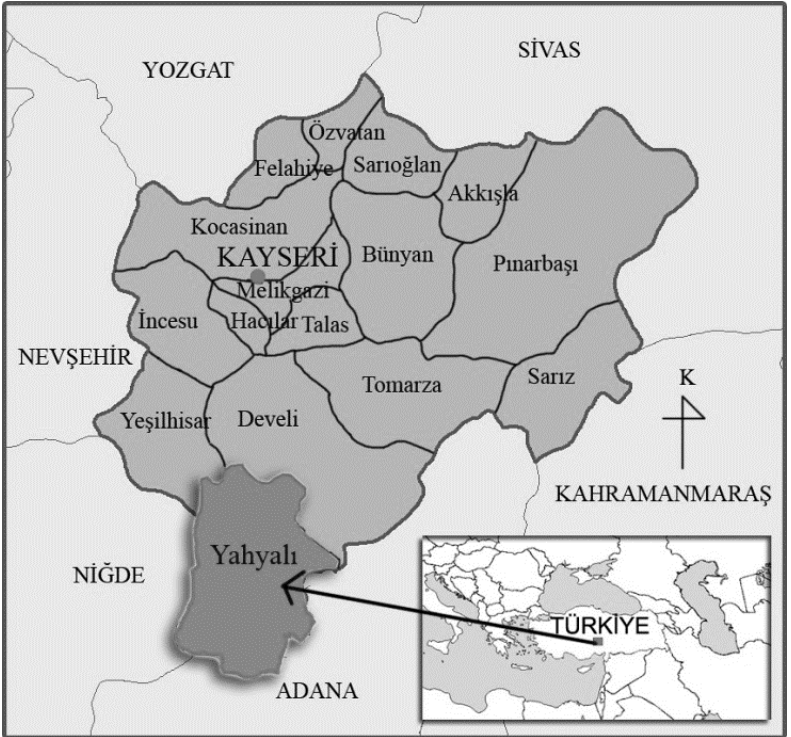

Şekil 1. Araștırma alanının konumu.

Orta Toroslar'ın en yüksek bölümünü oluşturan Aladağlar, alanın jeolojik ve jeomorfolojik yapısına şekil vermiştir. Dağın doğusundaki Zamantı Irmağı, batısındaki Ecemiş Çayı, devamındaki Körkün Çayı ve Çakıt Suyu ile bunlara katılan muhtelif dereler, derin vadiler ve yer yer kanyonlar oluşturmuştur (Somuncu, 2005). Su kaynakları bakımından zengin olan ilçede dik kayalıkların içinden çıkan şelaleler ilginç formu ve yükseklikleri ile başlıca turizm kaynaklarıdır.

Arazisinin yaklaşık \% 70'i dağlık olan ilçe, bitki örtüsü yönünden farklılıklar göstermektedir. Güneyinde geniş alanlar ormanla kaplı iken kuzeyde step bitki örtüsü hakimdir. İlçe'nin güneyinde Türkiye'deki yarı nemli ormanların en iyi geliştiği yerlerden biri olan Hacer Vadisi yer almaktadır. Pinus nigra Arn. subsp. pallasiana (Lamb.) Holmboe (karaçam) ve Juniperus sp. (ardıçlar)'ın oluşturduğu bu ormanlar içerisinde Cedrus libani A. Rich (Lübnan sediri) ve Abies cilicica (Ant. \& Kotschy) Carr. subsp. cilicica (Toros göknarı) diğer hakim türlerdir (Ünaldı ve Toroğlu, 2007). Orman vejetasyonunun yanı sıra yüksek dağ kesimleri alpin vejetasyonuyla dikkat çekmektedir.

\section{Yöntem}

Araştırma alanının görsel niteliği ile çekiciliği yüksek alanlarını ve peyzaj tiplerini ortaya koymak amacıyla algıya dayalı görsel kalite analizi yöntemi kullanılmıştır. Yöntemin temeli Daniel and Boster (1976) tarafından geliştirilen Manzara Güzelliği Değerlendirme Yöntemine (Scenic Beauty Estimation Method) dayanmaktadır. Yapılan bu çalışmada Clay and Daniel (2000), Daniel (2001), Arriaza ve ark. (2004), Meitner (2004) ve Çakcl (2007)'nin çalışmalarından faydalanılarak görsel kalite değerlendirme anket formu oluşturulmuştur.

Turizm ve rekreasyon faaliyetlerinin yoğunlukta olduğu Mayıs-Ağustos aylarında yapılan arazi çalışmalarında ilçenin karakteristik doğal ve kültürel kaynak değerleri olan şelale, orman, köy, dağ ve vadiler fotoğraflanmıștır. Profesyonel fotoğraf makinesiyle günün değişik zamanlarında, çekilen 2210 fotoğraf arasından her bir peyzaj tipini en iyi temsil eden 4'er fotoğraf (toplam 20 fotoğraf) seçilmiştir (Şekil 2). Fotoğraflar yansı yoluyla Mimarlık ve Tasarım Fakültesi (75), Ziraat Fakültesi (50) ve Fen Fakültesi'nden (50) toplam 175 öğrenciye sunularak görsel tercihlerine yönelik anket çalışması yürütülmüştür. Anketlerin değerlendirilmesinde 'SPSS 10.0' istatistik paket programı kullanılmıştır.

Fotoğraflar, algıya dayalı canlılık, renk etkisi, heyecan vericilik, rahatlatıcılık/huzur vericilik, ilginçlik, güven vericilik ve manzara güzelliği olmak üzere 7 parametre üzerinden 1 ile 5 arasında (1:çok düşük düzeyde, 2:düşük düzeyde, 3:orta düzeyde, 4:yüksek düzeyde, 5:çok yüksek düzeyde) puanlanlandırılmıştır. Birinci aşamada manzara güzelliği puanlarının ortalamalarına (M) göre katılımcların alandaki peyzaj tiplerini tercih öncelikleri değerlendirilmiştir. İkinci aşamada her bir peyzaj tipinde en yüksek manzara güzelliği puanı alan fotoğrafın diğer görsel kalite parametrelerinden aldığı puanlarla ilişkileri Spearman's korelasyon testi ile ortaya konmuştur.

\section{Bulgular ve Tartışma}

Yapılan araştırmada Yahyalı ilçesinin sahip olduğu farklı peyzaj tiplerinin görsel kalite analizinde katılımclar tüm fotoğraflara manzara güzelliği bakımından ortalamanın üzerinde puan vermişlerdir. Dolayısıyla ilçenin doğal ve kültürel kaynaklarının zenginliğine paralel olarak görsel kalitesinin de oldukça yüksek olduğu belirlenmiştir (Çizelge 1). 

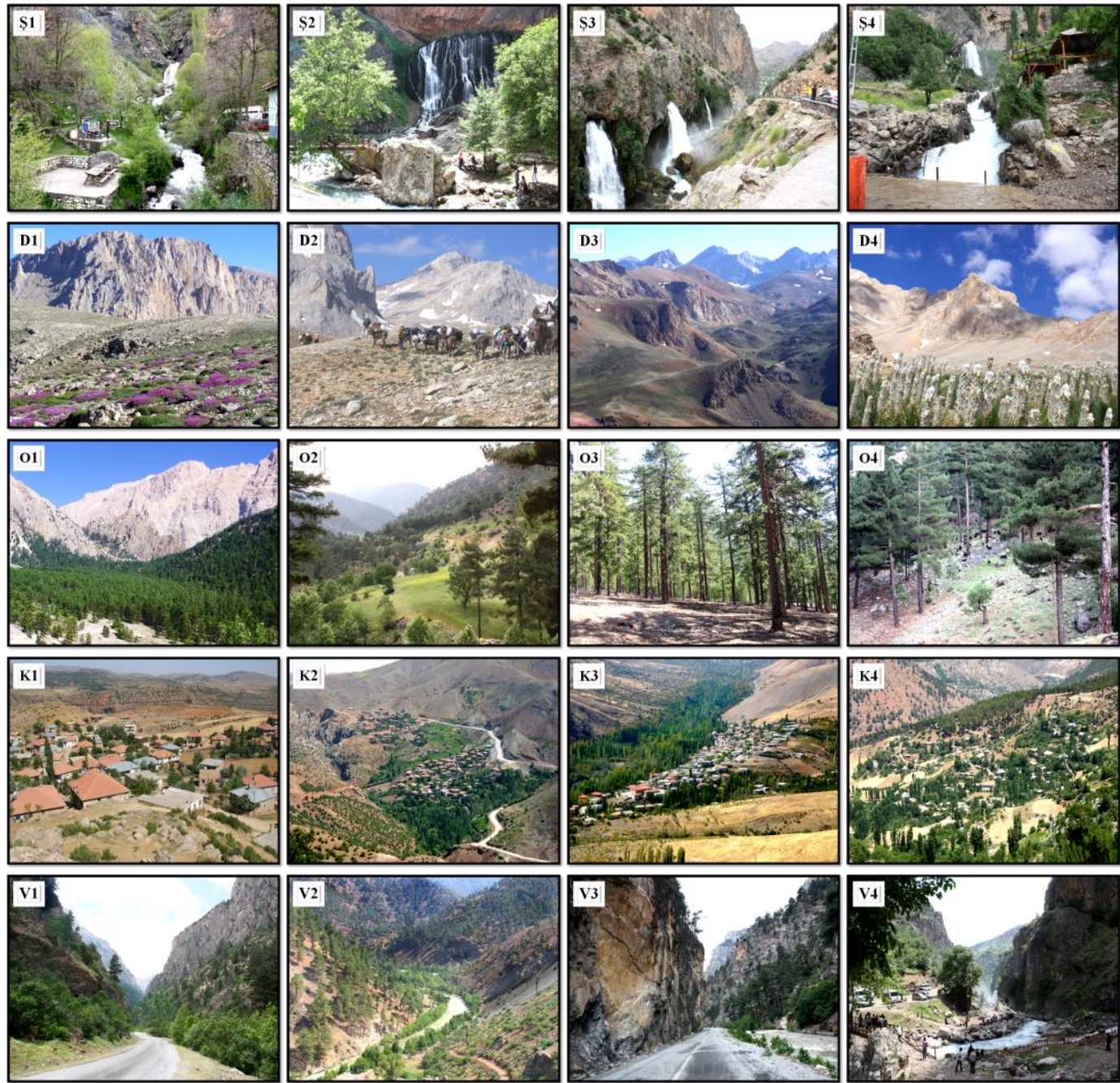

Şekil 2. Araştırma alanı görsel kalite analizinde kullanılan ve farklı peyzaj tiplerini temsil eden fotoğraflar.

Çizelge 1. Analizi yapılan görüntülerin görsel kalite puanı ortalamaları

\begin{tabular}{|c|c|c|c|c|}
\hline Peyzaj tipleri & Fotoğraf kodu & Örnek sayısı (N) & Manzara güzelliği puanları & Standart sapma \\
\hline \multirow{4}{*}{ Şelale } & Ș1 & 175 & 3.77 & 1.004 \\
\hline & $\$ 2^{*}$ & 175 & 3.83 & 1.107 \\
\hline & \$̧3 & 175 & 3.74 & 1.124 \\
\hline & Ș & 175 & 3.78 & 1.044 \\
\hline \multirow{4}{*}{ Dağ } & D1 & 175 & 3.29 & 1.093 \\
\hline & D2 & 175 & 2.87 & 1.112 \\
\hline & D3* & 175 & 3.62 & 1.262 \\
\hline & D4 & 175 & 3.60 & 1.119 \\
\hline \multirow{4}{*}{ Orman } & 01 & 175 & 3.57 & 1.053 \\
\hline & $02 *$ & 175 & 4.37 & 0.887 \\
\hline & 03 & 175 & 3.21 & 1.059 \\
\hline & 04 & 175 & 2.82 & 1.056 \\
\hline \multirow{4}{*}{ Köy yerleșimi } & K1 & 175 & 2.57 & 1.059 \\
\hline & $\mathrm{K} 2 *$ & 175 & 3.94 & 1.049 \\
\hline & K3 & 175 & 3.69 & 1.044 \\
\hline & $\mathrm{K} 4$ & 175 & 3.39 & 1.082 \\
\hline \multirow{4}{*}{ Vadi } & V1 & 175 & 3.55 & 0.957 \\
\hline & V2 & 175 & 4.03 & 1.028 \\
\hline & V3 & 175 & 3.21 & 1.201 \\
\hline & $\mathrm{V} 4 *$ & 175 & 4.19 & 0.933 \\
\hline
\end{tabular}

*Her bir peyzaj tipinde manzara güzelliği puanı en yüksek görüntü 
Anket sonuçlarına göre 5 ayrı peyzaj tipinde (şelale, dağ, orman, köy yerleşimi, vadi) manzara güzelliği bakımından şelalelere verilen puan ortalamasının en yüksek olduğu $(\mathrm{M}=3.78)$ belirlenmiștir. Şelaleleri sırasıyla vadi manzaraları $(\mathrm{M}=3.74)$, orman manzaraları $(M=3.49)$, köy yerleşimi görüntüleri $(\mathrm{M}=3.40)$ ve dağ manzaraları $(\mathrm{M}=3.34)$ takip etmiştir (Çizelge 2).

Çizelge 2. Peyzaj tiplerinin grup içi manzara güzelliği puanı ortalamaları

\begin{tabular}{cccc}
\hline Peyzaj tipleri & $\begin{array}{c}\text { Örnek } \\
\text { sayısı (N) }\end{array}$ & $\begin{array}{c}\text { Ortalama } \\
\text { puan (M) }\end{array}$ & $\begin{array}{c}\text { Standart } \\
\text { sapma }\end{array}$ \\
\hline Şelale & 175 & 3.78 & 0.037 \\
Vadi & 175 & 3.74 & 0.449 \\
Orman & 175 & 3.49 & 0.660 \\
Köy Yerleşimi & 175 & 3.40 & 0.596 \\
Dağ & 175 & 3.34 & 0.351 \\
\hline
\end{tabular}

Görsel kaliteyle ilgili yapılan değişik çalışmalarda su ögesi (Herzog, 1985; Hammitt ve ark., 1994; Arriaza ve ark., 2004), bitki örtüsü (Brown and Daniel, 1984; Ulrich, 1986; Ribe, 1990; Ramirez ve ark., 2011), biyolojik çeşitlilik (Van Den Berg ve ark., 1998; Clay and Smidt, 2004; Matthies ve ark., 2010; Yao ve ark., 2012), ormanlarla çevrili açık alanlar (Clay and Daniel, 2000), çiçekli çayırlıklar (Clay and Daniel, 2000) ve perspektif derinliği (Fuente de Val ve ark., 2006) görsel tercihi ve kaliteyi artıran unsurlar olarak ortaya konmuştur. Çalışmada her bir grup kendi içerisinde değerlendirildiğinde şelalelerden manzara güzelliği puanı en yüksek olan görüntünün Ş2 (Elif Şelalesi) olduğu belirlenmiştir $(\mathrm{M}=3.83)$. Dağ manzaralarından D3 $(\mathrm{M}=3.62)$ orman manzaralarından $02(\mathrm{M}=4.37)$, köy yerleşimlerinden K2 $(M=3.94)$ ve vadi manzaralarından V4'ün $(M=4.19)$ manzara güzelliği puanı en yüksek görüntüler olduğu ortaya çıkmıştır (Şekil 3).
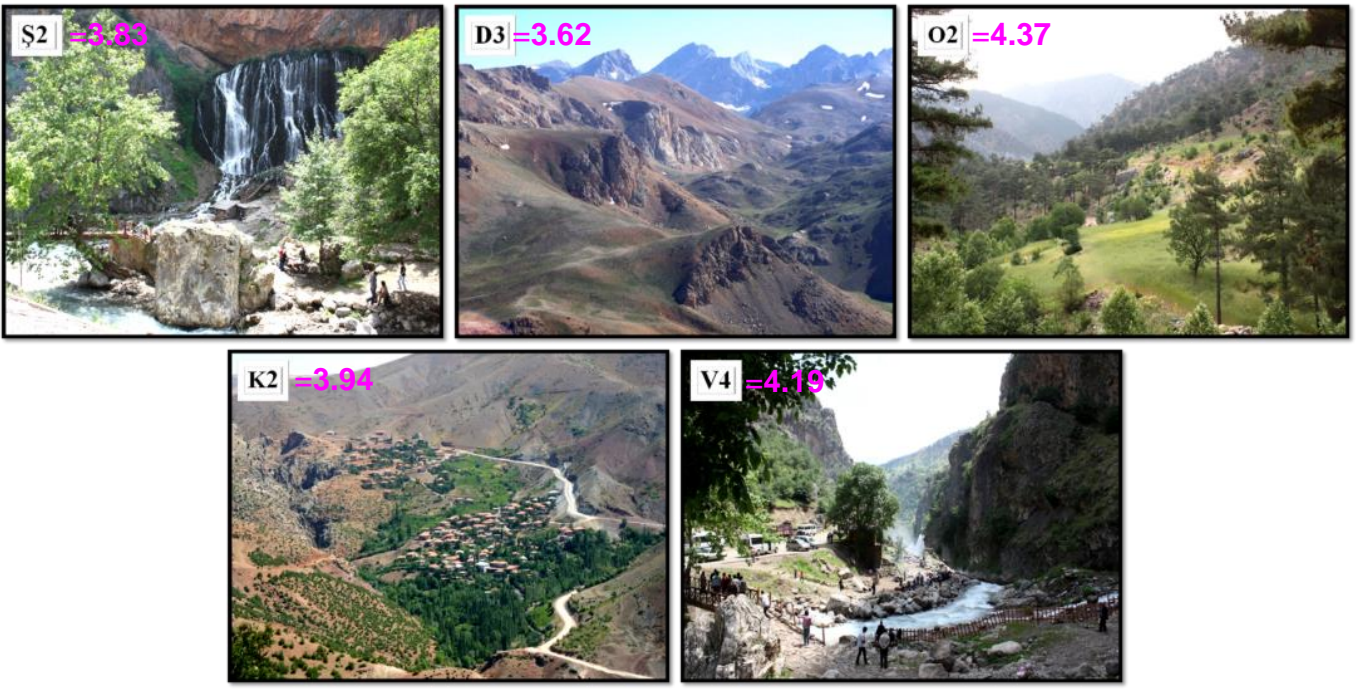

Șekil 3. Șelale, dağ, orman, köy ve vadi peyzajlarında manzara güzelliği puanı en yüksek olan görüntüler.

Peyzaj tipleri içerisinde manzara güzelliği puanı en yüksek fotoğraflar değerlendirildiğinde algllanırlı̆̆ı yüksek, perspektif derinliğine ve hareketli topoğrafyaya sahip alanların, dağların; su ve ağaçların yer aldı̆̆ı vadi oluşumları ile ormanlarla çevrili açık alanların insanlar tarafından en beğenilen alanlar olduğu saptanmıştır. Nitekim Arriaza ve ark. (2004)'ün yaptığı çalışma, bu bulguları destekler nitelikte olup görsel kalite bitkilerin kaplama yüzdesi, su miktarı, dağların varlığı, peyzajın doğallığı, iyi korunmuş insan yapımı unsurların varlığı ve renk etkisiyle ilişkilendirilmiştir. Yine yapılan çalışmalarda bitki, su vb. peyzaj elementlerinin alanın canlılığını, renk çeşitliliğini, uyumunu ve ilgi çekiciliğini artırarak rekreasyonel faaliyetlerde insanlar tarafindan daha çok tercih edildiği belirlenmiştir (Bulut ve ark., 2010).

İlçede çok sayıda mevsimlik şelalenin yanı sıra sürekli akışa sahip Kapuzbaşı, Elif, Güney ve Derebağ şelaleleri yer almaktadır. Şelalelerin bütünü kaya bloklarından çıkan, kaynağı görünmeyen, karstik kaynak şeklinde, yaz kış suları hiç eksilmeyen niteliklerde olup görenlerde hayranlık uyandırmaktadır. Bu şelalelerden görsel kalite analizinde en yüksek manzara güzelliği puanı alan Elif Şelalesi, yayvan akışlı olması, algılanırlığı yüksek açık bir peyzaj içerisinde bulunması, perspektife 
göre çınar ağaçları, kayalar ve ahșap bir köprünün arkasında fon oluşturması gibi özellikleriyle diğerlerinden ayrılmaktadır.

Görsel kalite analizinde manzara güzelliği bakımından şelale ve vadi oluşumlarından sonra üçüncü sırayı alan ormanlardan oluşan peyzaj tipinde ağaçlarla çevrili açık alanlar ile açık bir peyzaj içerisinde yer alan, dağların fon oluşturduğu hareketli topoğrafyadaki ormanlık alanların tercihinin daha yüksek olduğu ortaya çıkmıştır. Clay and Daniel (2000), görüntü derinliğinin algısallığı artırdığını ve manzara güzelliğiyle doğru orantılı olduğunu, bu nedenle arkası ormanla çevrili çayırlık açık alanların daha çok tercih edildiğini belirtmişlerdir. Bu bağlamda Kapuzbaşı köyünden sonra Hacer ormanlarının başladığı açık bir peyzaja sahip alçak kesimlerin rekreasyon potansiyelinin yukarı kesimlerdeki sık ve yüksek boylu ağaçlarla kaplı ormanlık alandan daha yüksek olduğu belirlenmiştir.

Çalışmada yerleşim tipi, topoğrafik yapısı ve bitki örtüsüyle birbirinden farklı özelliklere sahip köy yerleşimlerinin görsel analizinde yeşil dokuyla iç içe, dağınık olmayan köy yerleșimi en fazla tercih edilirken bunda perspektif derinliğinin ve algılanabilirliğin yüksek olmasının da etkili olduğu düşünülmektedir.

Aladağlar'ın değişik bölgelerinden çekilen fotoğrafların görsel analizi sonucunda alanın hareketli topoğrafyası en çok ilgi çeken özelliği olmuştur. Hammitt ve ark. (1994), Acar ve ark., (2006) ve Clay and Smidt (2004)'ün yaptı̆̆ çalışmalarda da manzara güzelliğiyle topoğrafik yapının pozitif ilişki gösterdiği ortaya konmuştur. Manzara güzelliğiyle renk faktörü arasında pozitif bir ilişki söz konusu olup çiçekli çayırlıklar, sadece yeșil çayırlara oranla insanların motivasyonunu daha çok artırmaktadır (Clay and Daniel, 2000). Bu çalışmada da dağ manzaralarının önünde belli alanı kaplayarak renk etkisi oluşturan çiçekli bitkilerin varlığının görsel tercihi arttırdığı belirlenmiştir.

Her bir peyzaj tipinde manzara güzelliği puanı en yüksek görüntünün diğer görsel kalite parametrelerinden aldığı puanların değerlendirildiği çalışmanın ikinci aşamasında manzara güzelliğinin canlılık, renk etkisi, heyecan vericilik, rahatlatıcıllk, ilginçlik ve güven vericilikle ilişkisinin istatistiki olarak çok önemli olduğu saptanmıştır $(\mathrm{p}<0,01)$.

Ş2'nin en yüksek puanı aldığı görsel kalite parametresi 'canlılık' olmuştur ( $M=3,71)$. Daha sonra 'heyecan vericilik' (M=3.58), 'rahatlatıcılı/huzur vericilik' $(M=3.49)$, 'ilginçlik' $(M=3.47)$, 'renk etkisi' $(M=3.31)$ ve 'güven vericilik' ( $M=2.96)$ parametreleri gelmiştir (Şekil 4). Bulut ve Yllmaz (2009)'un yaptıkları çalışmada kırsal alanlardaki şelalelerin görsel kalitesinin canlılık, uyum, büyüleyicilik, doğallık ve ilginçlik parametreleriyle ilişkili olduğu ortaya konulmuștur.

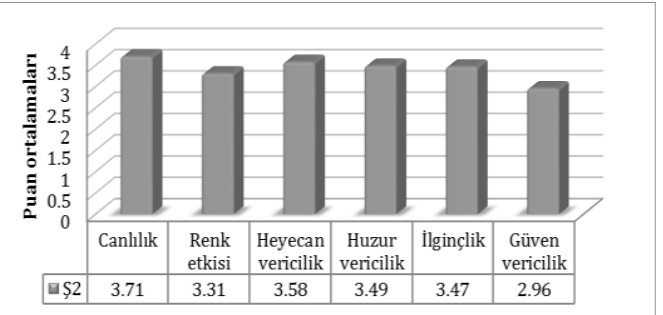

Şekil 4. Ş2'nin görsel kalite parametrelerinden aldığı puanların dağılımı.

Dağ manzaralarından D3 için en yüksek puanı alan parametre 3.61 puan ortalamasiyla canlılık olmuştur. Bunu sırasıyla heyecan vericilik $(M=3.52)$, renk etkisi ( $M=3.43)$, rahatlatıcllı/huzur vericilik $(M=3.19)$, ilginçlik $(M=3.18)$ ve güven vericilik $(\mathrm{M}=2.71$ ) takip etmektedir (Şekil 5).

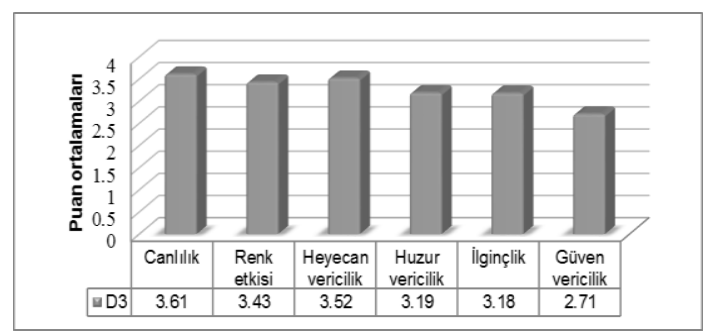

Şekil 5. D3'ün görsel kalite parametrelerinden aldığı puanların dağılımı.

Orman görüntülerinden manzara güzelliği puanı en yüksek olan görüntü 02 'dir. 02 görüntüsü canlılık görsel kalite parametresinde en yüksek puan ortalamasına sahiptir $(M=4.35)$. En düşük puanı alan parametre ise ilginçliktir (M=3.21). Şekil 6'da 02'nin görsel kalite parametrelerinde aldı $\breve{g}$ puanların dağılımı verilmiştir.

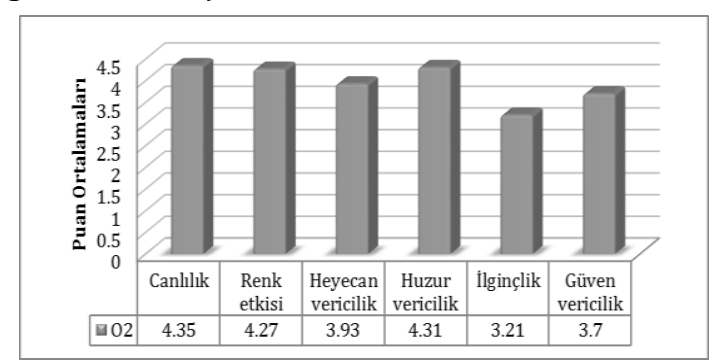

Şekil 6. 02'nin görsel kalite parametrelerinden aldığı puanların dağılımı. 
Köy yerleşimlerinden K2'de canlılık 3.89 ile en yüksek puanı alan parametre olurken bunu renk etkisi $(\mathrm{M}=3.83)$, heyecan vericilik $(\mathrm{M}=3.58)$, rahatlatıcılık/huzur vericilik $(M=3.55)$, ilginçlik $(M=3.25)$ ve güven vericilik $(M=3.19)$ takip etmiştir (Şekil 7).

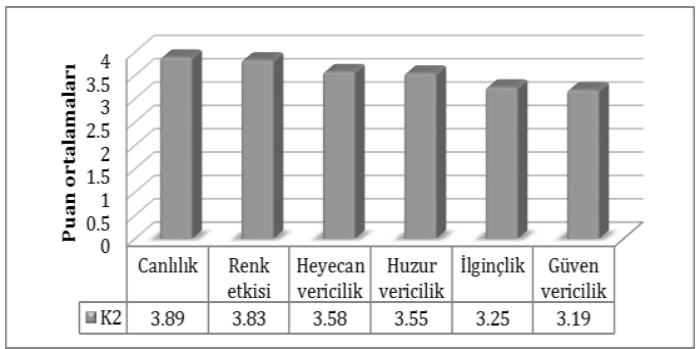

Şekil 7. K2'nin görsel kalite parametrelerinden aldığı puanların dağılımı.

Vadi görüntülerinden manzara güzelliği puanı en yüksek olan V4 canlılı (M=4.21) parametresinden en yüksek puanı alırken bunu sırayla rahatlatıcılık/huzur vericilik $(\mathrm{M}=3.87)$, heyecan vericilik $(M=3.78)$, renk etkisi $(M=3.76)$, güven vericilik $(M=3.27)$ ve ilginçlik $(M=3.26)$ takip etmiştir (Şekil 8).

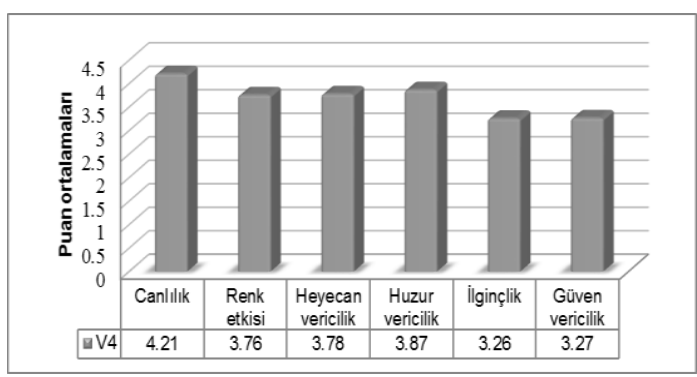

Şekil 8. V4'ün görsel kalite parametrelerinden aldığı puanların dağılımı.

Her bir peyzaj karakterinde en yüksek manzara güzelliği puanı alan fotoğrafın görsel kalite değerlendirme parametrelerine bakıldığında canlılık en yüksek puan alan parametre olmuștur. Manzara güzelliğinin canlılıkla ilişkisi istatistiki olarak çok önemli bulunmuştur $(\mathrm{p}<0,01)$. Benzer şekilde Clay and Smidt (2004), Acar ve ark., (2006), Eroğlu ve Acar (2011)'in çalışmalarında da görsel tercihte canlılık faktörünün etkili olduğu belirlenmiştir.

Yine görsel kalite parametrelerinden renk etkisi, heyecan vericilik, rahatlatıcılık, ilginçlik ve güven vericilik parametrelerine verilen puanlar arttıkça manzara güzelliği puanının da arttığı saptanmıștır $(\mathrm{p}<0,01)$. Yapılan çalışmalarda görsel tercihin renk etkisi (Clay and Daniel, 2000; Arriaza ve ark., 2004; Cañas ve ark., 2009; Yao ve ark., 2012), heyecan vericilik/büyüleyicilik (Acar ve ark., 2006) ve güven vericilikle (Kıroğlu, 2007) ilişkili olduğu ortaya konmuştur.

\section{Sonuç}

Turizm planlamalarında bir alanın doğal ve kültürel potansiyeliyle doğru orantılı olarak görsel kalitesi de artmaktadır. Nitekim görsel kalitenin temel ölçütlerinden manzara güzelliği turistik ve rekreasyonel aktivitelerde bir yerin çekiciliğini artırmakta, yapılan faaliyetlerin kalitesini doğrudan etkilemektedir (Clay and Daniel 2000).

Kayseri'nin güneyinde yer alan Yahyalı, topoğrafik yapısı nedeniyle çok farklı jeomorfolojik unsurlara sahip bir ilçedir. Bunun yanı sıra Akdeniz iklimi ile karasal iklim arasında geçiş gösteren iklimi sayesinde bitki örtüsü yönünden de çeșitlilik göstermektedir. Tüm bu özellikleriyle bulunduğu coğrafyadan farkl, karakteristik özelliklere sahip ilçede son yıllarda turizm faaliyetleri giderek artmaktadır. İlçede turizm faaliyetlerinin çeşitlendirilebilmesi ve önceliklerin belirlenmesi için tüm planlama çalışmalarında olduğu gibi doğal ve kültürel kaynakların çeşitli yönlerden analiz edilmesi gerekmektedir. Bu bağlamda görsel peyzaj analizi yapılan bu çalışmada farklı peyzaj tiplerini içeren Yahyalı ilçesinin görsel niteliğinin oldukça yüksek olduğu belirlenmiştir.

Görsel öncelik sıralamasına göre (1.) şelale, (2.) vadi, (3.)orman, (4.)köy ve (5.)dağ görüntülerinin tercih edildiği çalışmada, ilçenin güneyinde yer alan Zamantı ırmağı vadisini takip ederek Kapuzbaşı ve Elif Şelaleleri'ne oradan da Hacer ormanlarına devam eden güzergahın görsel kalitesinin oldukça yüksek olduğu saptanmıştır. Zengin su kaynakları, biyolojik çeşitliliği, jeomorfolojik özellikleri ve geleneksel köy yaşantılarıyla canlı, rahatlatıcı ve heyecan verici birçok peyzaj öğesini bir arada görmek mümkündür. Dolayısıyla mevcut turizm faaliyetlerinin yoğunlaştığı şelalelerin tek başına değil bölgenin bir koridor halinde doğal ve kültürel özelliklerinin korunmasına yönelik çalışmalar yapılması turizm faaliyetleri ve kaynakların sürdürülebilirliği bakımından önem arz etmektedir. Aladağlar, ilçedeki mevcut turizm faaliyetlerine alternatif bir alan niteliğindedir. Özellikle hareketli topoğrafyasıyla heyecan verici bulunan alan, Androsace villosa L., Anthemis cretica L., Asphodeline taurica, Centaurea urvillei, Gentiana verna L, Ornithogalum orthophyllum Ten., Thymus sp., Ranunculus demissus, Arabis caucasica Willd., Fritillaria aurea Schott, Onobrychis cornuta L., Scorzonera cana, Primula auriculata, Daphne oleides, 
Lamium sp., Jurinella moschus gibi alpin çiçekleriyle de dikkati çekmektedir.

\section{Kaynaklar}

Acar,C., Kurdoglu, B., Ç., Kurdoglu, O. Acar, H., 2006. Public preferences for visual quality and management in the Kackar Mountains National Park Turkey). International Journal of Sustainable Development \& World Ecology, 13 (6): 499-512.

Arriaza, M., Cañas-Ortega, J. F., Cañas, M. J., Ruiz-A. P., 2004. Asses the visual quality of rural landscapes. Landscape and Urban Plan, 69: 115-125.

Brown, T. C., Daniel, T. C., 1984. Modeling forest scenic beauty: Concepts and application to ponderosa pine. USDA Forest Service Research Paper, RM-256, Fort Collins, Colorado, 35 pp.

Bulut, Z., Sezen, I., Karahan, F., 2010. Determination of spring visual ceremonies of urban fruit trees and shrubs: A case study from Erzurum, Turkey. Journal of Food, Agriculture \& Environment, 8 (1): 289-296.

Bulut, Z., Yılmaz, H., 2009. Determination of waterscape beauties through visual quality assessment method. Environmental Monitoring and Assessment, 154:459-468.

Cañas, I., Ayuga, E., Ayuga, F., 2009. A contribution to the assessment of scenic quality of landscapes based on preferences expressed by the public. Land Use Policy, 26: 1173-1181.

Clay, G. R., Daniel, T. C., 2000. Scenic landscape assessment: the effects of land management jurisdiction on public perception of scenic beauty. Landscape and Urban Planning, 49 (1-2): 1-13.

Clay, G. R., Smidt, R. K., 2004. Assessing the validity and reliability of descriptor variables used in scenic highway analysis. Landscape and Urban Planning, 66 (4): 239-255.

Çakcı, I., 2007. Peyzaj Planlama Çalışmalarında Görsel Peyzaj Değerlendirmesine Yönelik Bir Yöntem Araştırması. Ankara Üniversitesi Fen Bilimleri Enstitüsü, Doktora tezi, Ankara, 109 s.

Daniel, T. C., 2001. Whither scenic beauty? Visual landscape quality assessment in the 21 st century. Landscape and Urban Planning, 54 (1-4): 267- 281.

Daniel, T. C., Boster, R. S., 1976. Measuring landscape esthetics: The Scenic Beauty Estimation Method. USDA Forest Service Research Paper, RM-167, Fort Collins, Colorado, $66 \mathrm{pp}$.

Eroğlu, E., Acar, C., 2011. Visual landscape character of Oriental spruce (Picea orientalis (L.) LINK.) mountain forests in Turkey. Journal of Environmental Engineering and Landscape Management, 19 (3): 189-197.
Fuente de Val, G., Atauri, J. A., Lucio, J. V., 2006. Relationship between landscape visual attributes and spatial pattern indices: Landscape and Urban Planning, 77 (4), 393-407.

Hammitt, W. E., Patterson, M. E., Noe, F. P., 1994. Identifying and predicting visual preference of southern Appalachian forest recreation vistas. Landscape and Urban Planning, 29: 171-183.

Herzog, T., R., 1985. A cognitive analysis of preference for waterscapes, Journal of Environmental Psychology, 5 (3): 225-241.

Kıroğlu, E., 2007. Erzurum Kenti ve Yakın Çevresindeki Bazı Rekreasyon Alanlarının Görsel Peyzaj Kalitesi Yönünden Değerlendirilmesi. Atatürk Üniversitesi Fen Bilimleri Enstitüsü, Yüksek lisans tezi, Erzurum, $185 \mathrm{~s}$.

Matthies, L., P., Briegel, R., Schüpbach, B., Junge, X., 2010. Aesthetic preference for a Swiss alpine landscape: The impact of different agricultural land-use with different biodiversity. Landscape and Urban Planning, 98: 99-109.

Meitner, M. J., 2004. Scenic beauty of river views in the Grand Canyon: relating perceptual judgments to locations. Landscape and Urban Planning, 68: 3-13.

Ramirez, A., Téllez, E., A., Gallego, E., Fuentes, J., M., García, A., I., 2011. A simplified model to assess landscape quality fro rural roads in Spain Agriculture. Ecosystems and Environment, 142: 205-212.

Ribe, R., G., 1990. A General Model for Understanding the Perception of Scenic Beauty in Northern Hardwood Forests. Landscape Journal, 9 (2): 86-101.

Somuncu, M., 2005. Aladağlar: Yaylacılık ve dağ göçebeliği konusunda bir araștırma. Gündüz eğitim ve yayıncllık, Ankara, $296 \mathrm{~s}$.

Ulrich, R. S., 1986. Human responses to vegetation and landscapes. Landscape and Urban Plan, 13: 29-44.

Ünaldı, Ü., E., Toroğlu, E., 2007. Aladağlar'da Bitki Formasyonları ve Dağılışları. Gazi Eğitim Fakültesi Dergisi, 27 (2): 227-240.

Van Den Berg, A., E., Vlek, C., A. J., Coeterier, J., F., 1998. Group differences in the aesthetic evaluation of nature development plans: A multilevel approach. Journal of Environmental Psychology, 18: 141-157.

Yao, Y., Zhu, X., Xu, Y., Yang, H., Wu, X., Li, Y., Zhang, Y., 2012. Assessing the visual quality of green landscaping in rural residential areas, Environ. Monit. Assess, 184: 951-967.

Zube, E.H., Sell, J.L., Taylor, J.G., 1982. Landscape perception: Research, application and theory. Landscape Planning, 9 (1): 1-33. 